\title{
Syndromic Retinitis Pigmentosa: Case Report of Usher Syndrome in Bamako
}

\author{
Théra JP${ }^{1 *}$, Tiama JM ${ }^{1}$, Konipo $A^{2}$ and Dakouo $P^{2}$ \\ ${ }^{1}$ Institute of African Tropical Ophthalmology, Bamako, Mali \\ ${ }^{2}$ Pediatric Ophthalmologist, Consultant CCBRT Hospital, Dar Es Salam, Tanzania \\ *Corresponding Author: Théra JP, Institute of African Tropical Ophthalmology, \\ Bamako, Mali.
}

Received: November 04, 2020

Published: November 25, 2020

(C) All rights are reserved by Théra JP., et al.

\begin{abstract}
Purpose: To report a very rare case of retinitis pigmentosa.

Case Report: We report the case of a 25-year-old man, admitted in the Institute of African Tropical Ophthalmology (IOTA) of Bamako for progressive visual acuity loss associated with deafness, in whom, after clinical investigation, the diagnosis of Usher syndrome type 2 was confirmed.

Discussion: Usher syndrome is a rare inherited genetic disorder. It is the first genetic cause associating retinal damage (retinitis pigmentosa) with hearing damage (deafness). Symptomatology varies according to the type.

Conclusion: Usher syndrome is a genetically diverse entity and is a leading cause of deaf-blindness. There is no specific care so far, but genetic counselling is of vital importance for its prevention.
\end{abstract}

Keywords: Usher; Retinitis Pigmentosa; Deafness

\section{Introduction}

Usher syndrome is defined as bilateral sensorineural hearing loss and vision loss caused by pigmentary retinopathy. It is the most common genetic cause of deafness and blindness in children. The symptoms were first described by the German ophthalmologist Albrecht von Graefe in 1858 [1]. but it was only in 1914 that a British ophthalmologist, Charles Usher, gave it a hereditary nature and gave it its current name [2]. Depending on the symptomatology, there are three types of Usher syndrome. The clinical diagnosis of Usher syndrome is established according to criteria defined by the Usher consortium [3]. At present there is no specific treatment for the syndrome, but gene therapy is currently being tested.

We report the case of a 25-year-old man who was admitted for progressive visual acuity loss associated with deafness and who was diagnosed with Usher syndrome type 2.

\section{Case Report}

This is a 25-year-old man admitted for progressive visual acuity loss at night over the past 10 years. He was born of a consanguine- ous marriage and is the first of five siblings. In his family there is a positive history of deafness. In fact, the $4^{\text {th }}$ male child who died at the age of 16 was complaining of nocturnal visual loss before his death; elsewhere, both parents were healthy. The clinical exam found a visual acuity of 6/60 in each eye. The biomicroscopic examination of the anterior segment was normal. At the fundus, there was a slight diffuse arteriolar narrowing, small vessels, papillary paleness, more pronounced retinal pigmented deposits on the periphery with bone spicules appearance and macular area dystrophy (Figure a-d). An ERG was performed and showed a decrease in response in scotopic and photopic, confirming the degeneration of retinal visual cells (rods and cones). An otorhinolaryngology examination was requested and found a hearing loss between 70 and 90 decibels corresponding to a severe hearing loss in tonal audiometry. The neurological check-up found no abnormalities.

The diagnosis of Usher syndrome type 2 was thus retained. The patient was referred to the department of low vision for management and to the geneticist for genetic counselling. 


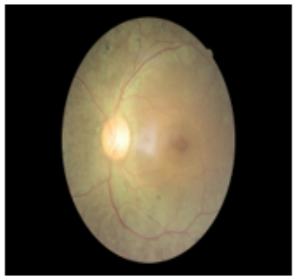

Figure a

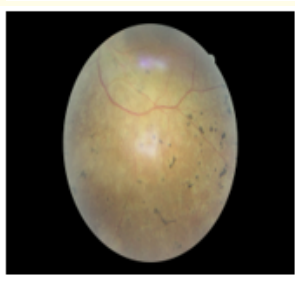

Figure c

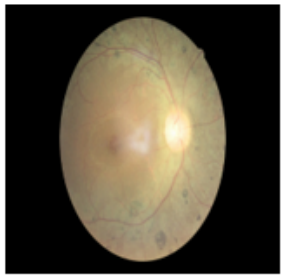

Figure b

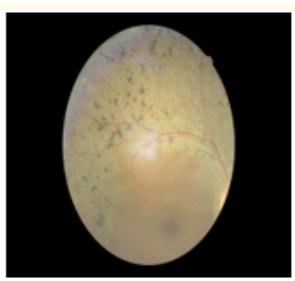

Figure d
Figure a,b,c and d: Photograph of the fundus centered on the posterior pole showing a decrease in vessels size, early papillary paleness and the dystrophic aspect of the macula. $\mathrm{c}$ and $\mathrm{d}$ : Shows the retinal periphery with pigmented migrations having the appearance of bone spicules.

\section{Discussion}

Usher syndrome (US) is the leading genetic cause of deafness associated with blindness in the world, with an estimated incidence of $1 / 6000$ births [4]. It represented $50 \%$ of the deaf-blind population in the USA [5]. Depending on the degree of hearing impairment, Usher syndrome has been classified into three types. Type 1 is characterized by profound congenital deafness, pigmentary retinopathy, and bilateral vestibular areflexia $[2,6]$.

Patients with Usher syndrome type 2 have moderate to severe congenital deafness, pigmentary retinopathy with preservation of vestibular function $[2,6]$. Usher syndrome type 3 is characterized by progressive hearing loss, pigmentary retinopathy and progressive vestibular deficit [7]. Our patient was severely deaf with vestibular function preserved as stated in Usher type 2. The impairment of visual function is related to the degree of pigmentary retinopathy. Some authors have found a more advanced form of pigmentary retinopathy in type 1 [8-10].

Our patient's visual acuity was 6/60 which classifies him as a category 1 visually impaired person according to the World Health Organization's classification of visually impaired people. This al- teration of central vision is related to cone dystrophy occurring at a slightly advanced stage of pigmentary retinopathy. Hearing impairment is common to all three types of Usher syndrome but at variable degrees. In type 2 as in our patient, deafness is moderate to profound. The progressive nature of deafness is specific to type 3. Genetically, all forms of Usher syndrome are transmitted in an autosomal recessive mode [11]. Both parents are therefore healthy carriers with a 25\% risk for each pregnancy. Currently, 10 responsible genes have been identified [12]. The two major genes are MYO7A and USH2A [13]. The diagnosis of Usher syndrome can be clinical; however today, molecular diagnosis is possible but it is expensive and inaccessible in most developing countries such as Mali. Electroretinogram (ERG) may be useful for the diagnosis of early pigmentary retinopathy but is of little diagnostic value in beginning or advanced cases. At the early stages, the ERG shows a decrease in scotopic response of the rods and overall responses but at an advanced stage the photopic responses decrease and the ERG is eventually abnormal.

At present, there is no specific treatment for Usher syndrome. Management must be multidisciplinary, involving ophthalmologists, otorhinolaryngologist, neurologist and speech therapist. Ophthalmological management is essentially based on low vision advice with prescription of filter lenses. A hearing aid can improve hearing in some cases, but the advice of specialists is essential. Studies on genetic therapy are ongoing. Finally, genetic counselling is necessary to assess and reduce the risk of transmission.

\section{Conclusion}

Usher syndrome is a genetically diverse entity and is a leading cause of deaf-blindness. There is no specific care so far, but genetic counselling is of vital importance for its prevention.

\section{Bibliography}

1. Von Graefe A. "Vereizelte Beobachtungen und Bemerkungen. Exceptionnelles verhalter des Gesichts feldes bei Pigmentenarter der Netzhalt". Arch Klin Ophthalmology 4 (1858): 250253.

2. Usher C. "On the inheritance of retinis pigmentosa, with notes of cases". Royal London Ophthalmology Hospital Reports 19 (1914): 130-236.

3. Smith RJ., et al. "Clinical diagnosis of the Usher syndromes. Usher Syndrome Consortium". American Journal of Medical Genetics 50 (1994): 32-38. 
4. Kimberling WJ., et al. "Frequency of Usher syndrome in two pediatric populations: Implications for genetic screening of deaf and hard of hearing children". Genetics in Medicine 12 (2010): 512-516.

5. Boughman JA., et al. "Usher syndrome: definition and estimate of prevalence from two high risk population". Journal of Chronic Diseases 36.8 (1983): 595-603.

6. Möller CG., et al. "Usher syndrome: an otoneurologic study". Laryngoscope 99 (1989): 73-79.

7. Pakarinen L., et al. "Usher syndrome type 3 (USH3): the clinical manifestations in 42 patients". Scandinavian Council of Logopedics and Phoniatrics 20 (1995): 141-150.

8. Fishman GA., et al. "Prevalence of foveal lesions in type 1 and type 2 Usher's syndrome”. Archives of Ophthalmology 113 (1995): 770-773.

9. Hope CI., et al. "Usher syndrome in the city of Birmingham prevalence and clinical classification". British Journal of Ophthalmology 81 (1997): 46-53.

10. Edwards A., et al. "Visual acuity and visual field impairment in Usher syndrome". Archives of Ophthalmology 116 (1998): 165-168.

11. Bonneau D., et al. "Usher syndrome type I associated with bronchiectasis and immotile nasal cilia in two brothers". Journal of Medical Genetics 30.3 (1993): 253-254.

12. György B., et al. "Rescue of hearing by gene delivery to innerear hair cells using exosome-associated AAV". Molecular Therapy 25 (2017): 379-391.

13. Maubaret C., et al. "Novel mutations in MYO7A and USH2A genes in Usher Syndrome". Ophthalmic Genetics 26.1 (2005): 25-29.

\section{Assets from publication with us}

- Prompt Acknowledgement after receiving the article

- Thorough Double blinded peer review

- Rapid Publication

- Issue of Publication Certificate

- High visibility of your Published work

Website: www.actascientific.com/

Submit Article: www.actascientific.com/submission.php

Email us: editor@actascientific.com

Contact us: +919182824667

Citation: Théra JP., et al. “Syndromic Retinitis Pigmentosa: Case Report of Usher Syndrome in Bamako". Acta Scientific Ophthalmology 3.12 (2020): $02-04$. 